\title{
Acquired Antibody to Factor XI in a Patient with Congenital Factor XI Deficiency
}

\author{
David M. Stern, Hymie L. Nossel, and John Owen, Department of Medicine, \\ Columbia University, College of Physicians \& Surgeons, New York 10032
}

A B S T R A C T The results of studies in a patient with congenital deficiency of Factor XI who developed an inhibitor are presented. The patient presented with a severe, apparently spontaneous bleed into the thigh, which progressed despite infusion of fresh frozen plasma, but which responded promptly to activated prothrombin complex. During therapy with plasma his clotting time and Factor XI level were unresponsive and a Factor XI inhibitor titer of $6,000 \mathrm{U} / \mathrm{ml}$ was attained. The inhibitor was isolated and found to be polyclonal immunoglobulin G (IgG), predominantly of subclass 4 . The specificity of the antibodies for Factor XI was shown by the ability of isolated inhibitor bound to polyacrylamide beads to remove Factor XI selectively from normal plasma. The binding of ${ }^{125} \mathrm{I}$ labeled factor XI to the inhibitor was studied and an affinity constant of $1.65 \times 10^{10} \mathrm{liter} / \mathrm{mol}$ was found. Complexing of the antibodies with Factor XI was shown to block multiple activities of the clotting factor. Factor XI complexed with antibody did not bind to high molecular weight kininogen or undergo activation and cleavage by two-chain Factor XII. The complex of activated Factor XI with inhibitor prevented the cleavage and activation of Factor IX. Hence the inhibitor appears to act by binding to multiple sites on the Factor XI molecule and preventing its interaction with other molecules. Clinically these interactions of the inhibitor with Factor XI result in a state of severe Factor XI deficiency.

The clinical circumstances of the case, with severe hemorrhage refractory to plasma infusion but readily responsive to an alternate clot-promoting agent, suggest that a defect of intrinsic system activation was critical, supporting the inference that Factor XI does participate in normal hemostasis. The clinical course of this patient, who has only had two documented hemorrhages in the presence of the inhibitor, is not as

Received for publication 9 October 1981 and in revised form 25 January 1982. severe as that of patients with severe Factor VIII or IX deficiency. This suggests that physiologic activation of Factors XI and IX does not occur exclusively in series because deficiency of factors XII, XI, VIII, and IX should then have similar hemostatic consequences. We propose that independent mechanisms for bypass of Factors XII and XI are important in physiologic activation of coagulation.

\section{INTRODUCTION}

The occurrence of antibodies to specific coagulation factors presents both problems and opportunities. Practically, bleeding episodes often respond poorly to replacement therapy necessitating other approaches. From the theoretical point of view the antibody provides a new tool for exploring the biology of its antigen. Factor XI, which links the contact coagulation factors with the intrinsic system via Factor IX, has an ill-defined role in the physiology of hemostasis. We are aware of only one report of a patient with congenital Factor XI deficiency who developed an antibody to the factor (1) and of four other cases, which have not been reported (T. Spaet and R. Mibashan. Personal communication). Systemic lupus erythematosus with a circulating anticoagulant and low Factor XI level has been reported (2). A patient seen by us with congenital deficiency of Factor XI and an acquired antibody presented with severe bleeding. The clinical manifestations of this patient and the properties of the antibody he developed are reported below.

\section{METHODS}

Case history. The patient (133-05-55) is a 49-yr-old man with congenital Factor XI deficiency. His course has been complicated by the development of an inhibitor. The patient's past history is remarkable for pentosuria and a lifelong bleeding diathesis. He bled excessively after tonsillectomy at age 10 and after nasal polypectomy at age 13 . At age 33 he was hospitalized for left submaxillary gland excision for chronic sialadenitis. Postoperatively, he bled twice, 
and on both occasions the hematomas required surgical drainage.

In 1965, he was hospitalized with an acute hematoma of the left anterior thigh. Radiographs obtained later showed densities consistent with a calcifying hematoma. Coagulation studies during 1965 showed a prolonged activated partial thromboplastin time (aPTT) ${ }^{1}$ of $182 / 79 \mathrm{~s}$ and a prothrombin time (PT) of $14.5 / 13.5 \mathrm{~s}$

In 1975 , the patient was readmitted for a right submandibular gland excision for chronic sialadenitis and removal of a sebaceous cyst of the back. Preoperative studies included $\mathrm{PT}=12.7 / 11.2, \quad$ aPTT $=180 / 62.9$, thrombin time $(\mathrm{TT})$ $=18.9 / 19$, fibrinogen $=280 \mathrm{mg} / \mathrm{dl}$, and bleeding time $=3^{\prime} 8^{\prime \prime}$ $\left(\mathrm{nl}<7^{\prime}\right)$. The factor XI level was $<1 \%$. Preoperatively, the patient received $10 \mathrm{U}$ of fresh frozen plasma (FFP) and the Factor XI level had increased to $32 \%$. 13 U of FFP were given over the first 3 postoperative $d$. The Factor XI level was $82 \%$ on the last infusion day and $<1 \% 3 \mathrm{~d}$ later. $\epsilon$-aminocaproic acid (Amicar; $24 \mathrm{~g} / \mathrm{d}$ ) was given for $5 \mathrm{~d}$.

In 1977, he presented with left thigh pain and swelling for $3 \mathrm{~d}$ without recognized trauma. Coagulation tests showed aPTT $=177.4 / 54 ;$ PT, TT, bleeding time, and fibrinogen levels were normal; and Factor XI assay $<1 \%$. He was admitted to the hospital and given $800 \mathrm{ml}$ FFP. Factor XI levels were $<1 \%$ both before and after infusion. A total of $40 \mathrm{U}$ of FFP were infused over the next $7 \mathrm{~d}$; for the first 3 d, $24 \mathrm{~g} / \mathrm{d}$ Amicar was given. On day 2, the Factor XI level increased from $<1 \%$ to $13.5 \%$ after the infusion of $5 \mathrm{U}$ of FFP; no inhibitor was found. Clinically, the hematoma appeared to be extending, and the patient's hematocrit was falling. Despite continuing FFP infusions, the Factor XI level was $<1 \%$ on day $3.6 \mathrm{~d}$ after the first FFP infusion, an inhibitor was clearly demonstrable, the hematocrit had fallen from 42.6 to $27.6 \%$, and there was progressive swelling of the lower extremity (Fig. 1). Between the 8th and 11th hospital days, he received a daily infusion of four bottles of Auto-Factor IX (Hyland Diagnostics Div., Travenol Laboratories, Costa Mesa, CA, lot HO 650-0024). Preinfusion tests on day 1 included aPTT $=245 / 54.8, \mathrm{PT}=13.4 / 12.0$, fibrin degradation products $<1 \mu \mathrm{g} / \mathrm{ml}$, fibrinogen $=610 \mathrm{mg} / \mathrm{dl}$, Factor XI <1\%. Tests drawn 3-5 min after infusion showed aPTT $=123 / 54.8, \mathrm{PT}=9.2 / 12.0 ; 1 \mathrm{~h}$ later, $\mathrm{PTT}=162 / 55, \mathrm{PT}=10.4 / 12.0 ; 2 \mathrm{~h}$ later, $\mathrm{aPTT}=96.4 /$ 55.0, $\mathrm{PT}=8.0 / 12.0 ; 3 \mathrm{~h}$ later $\mathrm{aPTT}=158 / 55, \mathrm{PT}=10.4 /$ 12.0. Fibrinogen and Factor XI levels were unchanged. During the following $3 \mathrm{~d}$, coagulation findings were similar. By day 2 of Auto-Factor IX therapy, the patient's leg was less swollen and less painful, and the hematocrit was stable. 7 $\mathrm{d}$ later, he was able to walk and was discharged $7 \mathrm{~d}$ thereafter without residual motor or sensory deficits.

In September 1978, he bled without injury into the left trapezius and pectoralis muscles and received 3,300 $\mathrm{U}$ of activated procomplex, which controlled the bleeding. In November 1981 the inhibitor titer was $90 \mathrm{U} / \mathrm{ml}$.

\footnotetext{
${ }^{1}$ Abbreviations used in this paper: Amicar, t-aminocaproic acid; BSA, bovine serum albumin; DFP, diisopropylfluorosphate; FFP, fresh frozen plasma; HMWK, high molecular weight kininogen; PBS, phosphate-buffered saline; PT, prothrombin time (patient/control); aPTT, activated partial thromboplastin time (patient/control); SDS-PAGE sodium dodecyl sulfate polyacrylamide gel electrophoresis; TBS, tris (hydroxymethyl) aminomethane-buffered saline (0.01 $\mathrm{M}$ tris $/ \mathrm{HCl}, \mathrm{pH} 7.5,0.14 \mathrm{M}$ sodium chloride); XII, activated two-chain Factor XII.
}

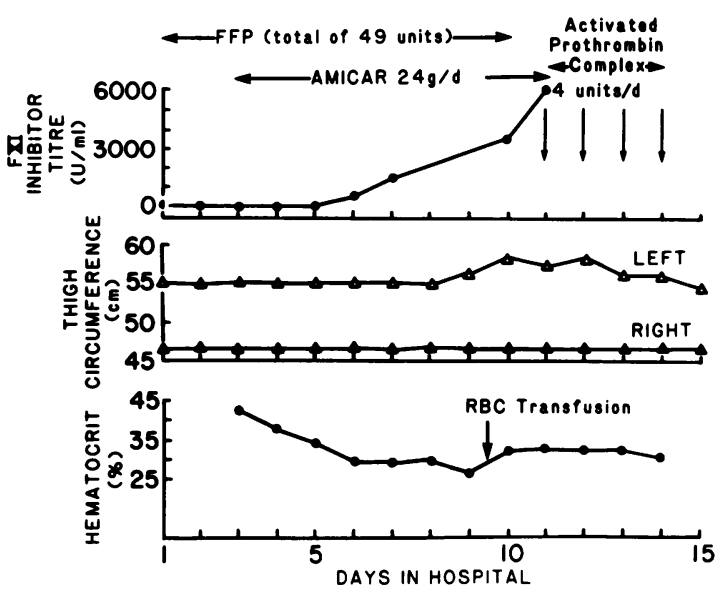

Figure 1 Clinical course of patient discussed in text. The patient was hospitalized with a massive hematoma of the left thigh. An inhibitor to Factor XI was first detected on day 6 by a coagulant assay. On day 7 , the thigh swelling began to increase and hematocrit continued to fall concomitant with a rapid rise inhibitor titre. $\mathrm{RBC}=$ erythrocytes.

Laboratory techniques. Factors IX and $\mathrm{X}$ were isolated with the assistance of Dr. W. Kisiel and Dr. E. Davie of the Department of Biochemistry, University of Washington, Seattle, WA. Human Factor XII and activated two-chain Factor XII (XIIa) were gifts of Dr. K. Fujikawa (University of Washington, Biochemistry Department). Some of the Factor XI used and all of the XIa were gifts of Dr. K. Kurachi and Dr. I. Ohkubo, both of the University of Washington, Biochemistry Department. High molecular weight kininogen (HMWK) and prekallikrein were gifts of Dr. A. Kaplan, Department of Medicine, State University of New York, Stony Brook, Long Island. Fibrinogen [Kabi fibrinogen further purified as described by Finlayson (4)] was a gift of Dr. J. Koehn from Dr. R. E. Canfield's laboratory in the authors' department. All the above reagents were prepared from human plasma. Reagents obtained commercially were in all instances the highest quality available.

Partial purification of inhibitor. The inhibitor was partially purified by sequential $40 \%$ ammonium sulfate precipitation, DEAE (A-50) Sephadex (5), protein A-Sepharose CL4B (6), and Sephacryl S-200 chromatography (Pharmacia Fine Chemicals, Div. of Pharmacia Inc., Piscataway, NJ). The final product was characterized by immunodiff usion and sodium dodecyl sulfate polyacrylamide gels (SDS-PAGE). IgG was isolated in an identical manner from normal human pooled plasma and was free of Factor XI activity.

Preparation and use of immunoadsorbents. Normal rabbit serum and rabbit antisera to human immunoglobulins (heavy and light chains; N. L. Cappel Laboratories Inc., Cochranville, PA) were chromatographed on protein A-Sepharose CL-4B, and the eluted material (6) was coupled to CNBr-activated sepharose 4B (Pharmacia Fine Chemicals) following the manufacturer's directions (7). Normal swine and rabbit antisera to human IgG heavy chain subclasses (Nordic Laboratories, El Toto, CA) were chromatographed on DEAE-affi-gel blue (Bio-Rad Laboratories, Richmond, CA) and the pass through fractions similarly pooled and coupled to CNBr-activated sepharose. After checking the adsorptive capacity (8) and specificity (9) of the columns, diluted patient plasma or partially purified inhibitor was 
TABLE I

Immunological Characterization of the Factor XI Inhibitor using Sepharose

Coupled Specific Antisera to Human Immunoglobulins

\begin{tabular}{|c|c|c|c|c|}
\hline \multirow{2}{*}{$\begin{array}{c}\begin{array}{c}\text { Column specific } \\
\text { protein }\end{array} \\
\text { Anti-human }\end{array}$} & \multicolumn{2}{|c|}{ Pass-through fractions } & \multicolumn{2}{|c|}{$4 \mathrm{M}$ Guanidine eluate } \\
\hline & $\begin{array}{l}\text { Inhibitor } \\
\text { activity }\end{array}$ & $\begin{array}{c}\text { Presence of } \\
\text { column specific } \\
\text { protein }\end{array}$ & $\begin{array}{l}\text { Inhibitor } \\
\text { activity }\end{array}$ & $\begin{array}{c}\text { Presence of } \\
\text { column specific } \\
\text { protein }\end{array}$ \\
\hline$\gamma^{\circledast}$ & 0 & $\mathbf{0}$ & +++ & ++ \\
\hline$\alpha^{\otimes}$ & ++++ & 0 & 0 & ++ \\
\hline$\mu^{\otimes}$ & ++++ & 0 & 0 & ++ \\
\hline $\mathbf{K}$ & ++ & $\mathbf{0}$ & ++ & ++ \\
\hline$\lambda$ & ++ & 0 & ++ & ++ \\
\hline $\operatorname{IgG}_{1}$ & ++++ & ND & 0 & $(++)^{\circ}$ \\
\hline $\operatorname{IgG}_{2}$ & +++ & ND & 0 & $(++)^{\circ}$ \\
\hline IgG $_{3}$ & ++++ & ND & 0 & $(++)^{\circ}$ \\
\hline $\mathrm{IgG}_{4}$ & 0 & ND & ++ & $(++)^{\bullet}$ \\
\hline
\end{tabular}

Purified inhibitor was applied to each column. The pass-through fractions and the 4-M guanidine- $\mathrm{HCl}$ eluate were assayed. Inhibitor activity was detected by coagulant assay. Specificity and completeness of immunoadsorption were determined using Ouchterlony plates and radial immunodiffusion as described in text. ND $=$ not done, $(++)^{\circ}=$ IgG present in eluate, $\otimes=$ experiments done with inhibitor plasma in addition to purified inhibitor.

applied to the column, and pass-through and $4 \mathrm{M}$ guanidine eluate were collected. Inhibitory activity was determined by coagulant assay or ability to bind ${ }^{125}$ I-Factor XI (below).

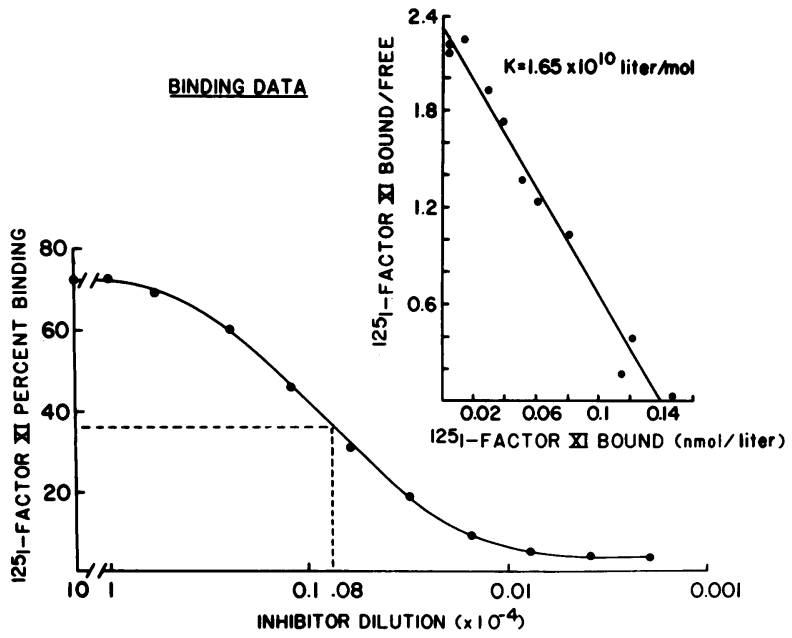

FIgure 2 Binding curve of inhibitor and ${ }^{125} \mathrm{I}-\mathrm{F}$ actor XI (lower figure). ${ }^{125} \mathrm{I}$-Factor XI was incubated with varying dilutions of inhibitor as described in Methods (binding studies). The dashed line represents $50 \%$ binding. Each point plotted represents the mean of triplicates. Scatchard plot of inhibitor and Factor XI (upper figure). ${ }^{125}$ I-Factor XI, varying amounts of unlabeled Factor XI and inhibitor plasma (at $10^{-5}$ dilution) were incubated for $16 \mathrm{~h}$ at $37^{\circ} \mathrm{C}$. Staphylococcal-bound protein $A$ was added and the samples processed as above. The affinity constant was $1.65 \times 10^{10}$ liter/ mol, and the apparent antibody concentration in the patient's plasma was $0.7 \times 0.1 \mathrm{nM}$ (this sample had 6,000 $\mathrm{U}$ of inhibitor per milliliter). Each point plotted is the mean of triplicates.
Purification of Factors XI and IX. Factor XI was purified by a modification of the methods of Heck and Kaplan (10) and Bouma and Griffin (11) using sequential DEAE Sephadex (A-50), SP Sephadex (C-50), Sephadex G-150 chromatography (Pharmacia Fine Chemicals), and IgG immunoadsorption [Kaplan's (12) column was used]. The sp act was $19 \mathrm{U} / \mathrm{mg}$. Prekallikrein activity was absent. SDS-PAGE (13) showed a single band of mol wt 160,000 unreduced and mol wt 80,000 reduced. ${ }^{125}$ I-Factor XI labeled by the chloramine $T$ method retained full coagulant activity over the 1 wk it was used (stored at $-70^{\circ} \mathrm{C}$ ) and migrated identically to unlabeled material on SDS-PAGE.

Factor IX purified by the method of Kisiel and Davie (14) showed a single band reduced or unreduced of $55,000 \mathrm{~mol}$ wt on $10 \%$ SDS-PAGE with a sp act of $1,700 \mathrm{U} / \mathrm{mg}$. Factor $\mathrm{X}$ coagulant activity was not detectable. ${ }^{125} \mathrm{I}$-Factor IX labeled by the chloramine $T$ method as modified by Thompson (15) migrated identically to unlabeled material on SDSPAGE and retained full clotting activity over the 1 wk it was used (stored at $-70^{\circ} \mathrm{C}$ ).

Binding studies. Binding of ${ }^{125} \mathrm{I}-\mathrm{F}$ actor $\mathrm{XI}$ to the Factor $\mathrm{XI}$ inhibitor was determined as follows: $0.1 \mathrm{ml}$ of dilutions of sample [in $0.01 \mathrm{M}$ sodium phosphate ( $\mathrm{pH} 7.5$ ), $0.5 \mathrm{M}$ sodium chloride, $1 \%$ bovine serum albumin (BSA)] and $0.1 \mathrm{ml}$ of inhibitor plasma $\left(10^{-5}\right.$ dilution) was added to ${ }^{125} \mathrm{I}$-Factor $\mathrm{XI}\left(10^{4} \mathrm{cpm}\right)$. After $16 \mathrm{~h}$ at $37^{\circ}, 0.1 \mathrm{ml}$ of IgGSorb (protein $A$ bound to staphylococcus made by The Enzyme Center, Inc., Boston, MA) was added to each tube, and the tubes were incubated for $30 \mathrm{~min}$ (agitating every $3 \mathrm{~min}$ ). $2 \mathrm{ml}$ of buffer was added to each tube, which was then centrifuged at $3,500 \mathrm{rpm}$ for $4 \mathrm{~min}$. The supernatant was aspirated and the pellet counted. Assays were done in triplicate using siliconized tubes. ${ }^{125} \mathrm{I}$-Factor XI inhibitor binding reached equilibrium after $16 \mathrm{~h}$ of incubation and protein $\mathrm{A}-\mathrm{im}$ munoglobulin equilibrium binding was reached within 30 $\min$.

Specificity of binding. Specificity of binding was studied by adding samples to the above assay system. Activated clotting Factors (XIIa, XIa) were tested with and without prein- 
cubation for $90 \mathrm{~min}$ at $37^{\circ} \mathrm{C}$ with diisopropylfluorosphate (DFP) $(5 \mathrm{mM}$ final concentration). Test solutions contained factors IX, X, XI, or fibrinogen (each $1 \mathrm{mg} / \mathrm{ml}$ and doubling dilutions), Factor XII ( $0.4 \mathrm{mg} / \mathrm{ml}$ and doubling dilutions), or buffer. Prekallikrein and high molecular weight kininogen were radiolabeled using the chloramine $T$ method (16). Both tracers retained coagulant activity. Binding studies using these tracers were performed as above and with longer incubation times $(24$ and $48 \mathrm{~h})$, lower temperature $\left(4^{\circ} \mathrm{C}\right.$, $\left.23^{\circ} \mathrm{C}\right)$, and lower ionic strength of the buffer $(0.14 \mathrm{M}$ or 0.08 $\mathrm{M} \mathrm{NaCl}$ ).

Effect of immobilized inhibitor on clotting tests of normal plasma. Citrated pooled plasma from normal volunteers, inhibitor plasma, purified control IgG, and inhibitor IgG (prepared as above) were coupled to polyacrylamide beads (Immunobead Matrix, Bio-Rad Laboratories) using 1ethyl-3 (3-dimethylaminopropyl) carbodiimide $\mathrm{HCl}$ following the manufacturer's protocol. Resin $(0.1 \mathrm{ml}$ settled volume) and plasma $(0.3 \mathrm{ml})$ were added to each tube, and the mixtures were agitated for $55 \mathrm{~min}$. After centrifugation the supernatant fluid was assayed (see below).

Factor IX activation. Factor IX activation was assessed as described by Osterud and Rapaport (17) by following cleavage of ${ }^{125} \mathrm{I}-\mathrm{Fact}$ or IX on $10 \%$ reduced SDS-PAGE. Purified inhibitor or normal human IgG was added to Factor $\mathrm{XIa}(8,6,4,2,0.8$, or $0.2 \mu \mathrm{g} / \mathrm{ml})$ or contact product (18) or tris(hydroxymethyl)aminomethane-buffered saline (TBS). Details of the procedure are in the legend to Fig. 4.

Factor XI activation. Factor XI activation was assessed by following cleavage of ${ }^{125} \mathrm{I}$-Factor XI on $10 \%$ SDS-PAGE (11). ${ }^{125} I-F$ actor XI was incubated with purified inhibitor (adjusted to a titer comparable to that in the patient's plasma) or purified control human IgG for $2 \mathrm{~h}$ at $37^{\circ} \mathrm{C}$. Then either two-chain human Factor XIIa $(0.2,2,4,10 \mu \mathrm{g} / \mathrm{ml}$ were used in separate experiments) or $5 \mu \mathrm{l}$ of contact product (prepared from Factor XI-deficient plasma), or TBS was added. The procedure is further described in the legend to Fig. 5.

HMWK binding. HMWK was immobilized on the surface of polypropylene tubes as described by Thompson et al. (19) using either $\mathrm{HMWK}$ at $5 \mu \mathrm{g} / \mathrm{ml}$ or BSA at $10 \mathrm{mg}$ /

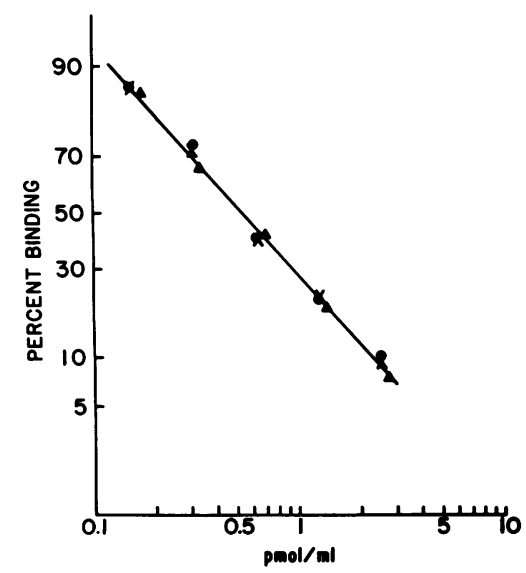

FIGURE 3 Comparative inhibition of binding. ${ }^{125}$ I-Factor XI and inhibitor plasma $\left(10^{-5}\right.$ dilution) were incubated with varying amounts of unlabeled Factors XI, XIa, and XIa-DFP (XIa-DFP = XIa preincubated with DFP as described above) at $37^{\circ} \mathrm{C}$ for $16 \mathrm{~h}$. Staphylococcal-bound protein A was added and the samples processed as described in the text. Tracer: $\Delta=F X I ; X=$ FXI $_{\mathrm{a}} ; \boldsymbol{0}=\mathrm{FXI}_{\mathrm{a}}$-DFP.
TABLE II

Effect of Immobilized Inhibitor on Clotting Tests of Normal Plasma

\begin{tabular}{|c|c|c|c|c|}
\hline \multirow[b]{2}{*}{$\begin{array}{l}\text { Protein coupled to } \\
\text { resin }\end{array}$} & \multicolumn{4}{|c|}{ Clotting tests $(8)$} \\
\hline & PT & aPTT & $\begin{array}{c}\text { Factor } \mathrm{XI} \\
\text { assay }\end{array}$ & $\begin{array}{l}\text { aPTT after } \\
\text { addition of } \\
\text { factor } \mathrm{XI}^{-}\end{array}$ \\
\hline Normal plasma & $15.6 \mathrm{~s}$ & $78.2 \mathrm{~s}$ & $98 \%$ & \\
\hline Patient plasma & 15 & 254.6 & $<1 \%$ & $77.3 \mathrm{~s}$ \\
\hline Normal IgG & 15.1 & 77.6 & $97 \%$ & \\
\hline Inhibitor IgG & 15.5 & 259.3 & $<1 \%$ & $77.6 \mathrm{~s}$ \\
\hline
\end{tabular}

$0.10 \mathrm{ml}$ of resin coupled to plasma (normal or patient) or purified IgG (normal or patient) was incubated with $0.3 \mathrm{ml}$ of normal plasma (continuous mixing) for $55 \mathrm{~min}$. at $37^{\circ} \mathrm{C}$. The mixture was centrifuged $\left(2,500 \mathrm{rpm} ; 6 \mathrm{~min} 23^{\circ} \mathrm{C}\right)$ and the supernatant was assayed (see text for details). Each time or percent given is the average of triplicates. Normal pooled plasma incubated for $55 \mathrm{~min}$ was used as standard for the assay. Before incubation, the aPTT was $63 \mathrm{~s}$ and the PT $15.5 \mathrm{~s}$.

- $5 \mu \mathrm{g} / \mathrm{ml}$ purified Factor XI was added.

$\mathrm{ml}$ in 0.01 sodium phosphate ( $\mathrm{pH} 8.0$ ) containing $0.14 \mathrm{M}$ sodium chloride, $1 \mathrm{mM}$ DFP (PBS/DFP) to coat the tubes. Each coated tube received $0.1 \mathrm{ml}$ of ${ }^{125} \mathrm{I}-\mathrm{Factor} \mathrm{XI}$ or ${ }^{125} \mathrm{I}$ Factor XI (in PBS/DFP containing $10 \mathrm{mg} / \mathrm{ml}$ BSA), which had been preincubated for $16 \mathrm{~h}$ with either PBS/DFP containing control IgG or purified inhibitor. HMWK-coated tubes were preincubated with purified inhibitor, then washed and incubated with ${ }^{125} \mathrm{I}-\mathrm{Factor} \mathrm{XI}$. All tubes were incubated with tracer overnight at $23^{\circ} \mathrm{C}$, aspirated, and washed with PBS/DFP four times before counting.

Coagulation assays. The Factor XI inhibitor was assayed by incubating equal volumes of inhibitor plasma and normal plasma for $1 \mathrm{~h}$ at $37^{\circ} \mathrm{C}$, and then assaying $0.1 \mathrm{ml}$ of the mixture for Factor XI activity as described (20). One inhibitor unit was defined as the amount of inhibitor required to activate $50 \%$ of $\mathrm{Factor} X I$ activity in $1 \mathrm{~h}$ at $37^{\circ} \mathrm{C}$ as compared with the control.

In assays for Factors VIII, IX, X, XII, prekallikrein, and HMWK, the Factor XI-deficient plasma (George King Biochemical, Overland Park, KS) was replaced by the appropriate congenitally deficient plasma. The activated partial thromboplastin time and the prothrombin time were measured as described (20).

\section{RESULTS}

Partial purification and immunological characterization of Factor XI inhibitor. Partially purified inhibitor eluted as a symmetrical peak from Sephacryl S-200 corresponding to a mol wt of 160,000 . 7.5\% SDS PAGE showed a single band of mol wt, 160,000 , unreduced and two chains (mol wt 53,000 and 25,000) reduced. The inhibitory activity of unfractionated patient plasma had the same elution volume on Sephacryl S-200.

Immunoadsorption experiments using patient plasma and partially purified inhibitor ${ }^{2}$ demonstrated that the

${ }^{2}$ Anti- $\alpha$-immunoadsorption of purified inhibitor after the final gel filtration step was necessary to remove a small 


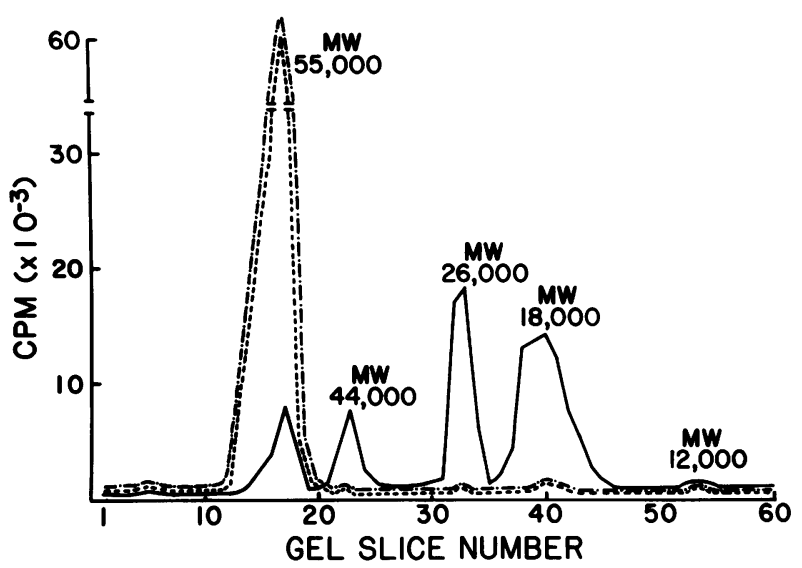

FIGURE 4 Cleavage products of FIX activation (10\% SDS gels, reduced). $10 \%$ SDS-PAGE of reduced ${ }^{125}$ I-Factor IX (- - : mol wt 55,000) showing cleavage pattern with formation of Factor IXa [ $(-$; consisting of heavy chain (mol wt 26,000), light chain (mol wt 18,000), and activation peptide (mol wt 12,000)] by Factor XIa or celite-adsorbed activated contact product (see text). - - - shows the radioactivity profile of ${ }^{125} \mathrm{I}-\mathrm{F}$ actor IX if the Factor XIa or celiteactivated contact product was preincubated with purified patient IgG. In the experiment shown, $5 \mu$ l of Factor XIa $(2 \mu \mathrm{g} / \mathrm{ml})$ was preincubated with $5 \mu \mathrm{l}$ of partially purified inhibitor at $37^{\circ} \mathrm{C}$ followed by the addition of ${ }^{125} \mathrm{I}$-Factor IX $(0.4 \mu \mathrm{g} / \mathrm{ml})$ and $5 \mu \mathrm{l}$ of $50 \mathrm{mM} \mathrm{CaCl}$. After $90 \mathrm{~min}$ at $37^{\circ} \mathrm{C}$ the reaction was terminated with $10 \mu \mathrm{l}$ of $0.6 \mathrm{M}$ EDTA, 18 $\mu \mathrm{l}$ of $6 \%$ SDS and $5 \mu \mathrm{l}$ of 2 -mercaptoethanol. The sample was boiled, then $3 \mu \mathrm{l}$ of $0.05 \%$ bromphenol blue in $50 \%$ sucrose was added and $10 \mu \mathrm{l}$ applied to $10 \%$ SDS-PAGE.

inhibitor activity was entirely IgG. Both $\kappa$ and $\lambda$ immunoadsorbents-retained inhibitor activity was predominantly $\mathrm{IgG}_{4}$, but a small amount of inhibitor activity was retained on the $\operatorname{IgG}_{2}$ immunoadsorbent (Table I). Immunodiffusion plates confirmed the presence of only $\gamma$-heavy chain and both $\kappa$ and $\lambda$-light chains in the partially purified preparation.

Binding curve and Scatchard Plot for ${ }^{125}$ I-Factor $X I$. The sigmoidal binding curve showed maximal (72-78\% of the available counts) ${ }^{125}$ I-Factor XI binding by $10^{-2}$ to $10^{-4}$ dilution of inhibitor plasma and $50 \%$ tracer binding at $8 \times 10^{-6}$ dilution (Fig. 2). These binding studies were conducted at equilibrium (16 h at $37^{\circ} \mathrm{C}$ ). A Scatchard plot gave a straight line with an association constant of $1.65 \times 10^{10} \mathrm{liter} / \mathrm{mol}$, giving a concentration of $1.4 \times 10^{-10} \mathrm{~mol} /$ liter binding sites in the patient's plasma. For IgG with two identical binding sites this would be a concentration of $1 \mathrm{mg} /$ $\mathrm{ml}$ of inhibitor antibody in the plasma sample with a titer of $6,000 \mathrm{U} / \mathrm{ml}$.

Specificity of ${ }^{125 I-F a c t o r ~ X I ~ b i n d i n g . ~ F a c t o r s ~ X I, ~}$ $\mathrm{XIa}$, and XIa-DFP behaved identically in inhibiting

amount of residual $\operatorname{IgA}$. There was no loss of inhibitory activity after removal of this IgA. the binding of ${ }^{125} \mathrm{I}-\mathrm{Factor}$ XI by inhibitor plasma (Fig. 3). Binding of ${ }^{125}$ I-Factor XI was not inhibited by Factor XII, two-chain Factor XIIa, Factor IX, fibrinogen, or Factor $\mathrm{X}$ under the conditions described or with longer incubation times, lower temperature, or reduced ionic strength. DFP did not affect the binding of activated clotting factors. The inhibitor did not bind ${ }^{125}$ I-HMWK and only a maximum of $1-2 \%{ }^{125}$ I-prekallikrein was bound at very high concentrations $\left(10^{-2}\right)$ of inhibitor plasma.

Effects of immobilized inhibitor on clotting tests of normal plasma. Patient plasma or partially purified inhibitor bound to polyacrylamide beads markedly prolonged the partial thromboplastin time of normal plasma and selectivity decreased Factor XI coagulant activity. Both the partial thromboplastin time and Factor XI level were corrected by addition of purified Factor XI (Table II). The coagulant activity of Factors VIII, IX, XII, prekallikrein, high molecular weight kininogen, and the prothrombin time were not different in normal plasma exposed to beads coated with inhibitor or with normal whole plasma or partially purified IgG.

Effect of inhibitor on the cleavage of Factor IX by Factor IXa. Factor XIa cleaved ${ }^{125}$ I-Factor IX to form Factor IXa (mol wt 44,000) with heavy chain (mol wt 26,000 ), light chain (mol wt 18,000), and activation peptide (mol wt 12,000) (22) as clearly shown by SDSPAGE of reduced protein (Fig. 4). Preincubation of Factor XIa with the inhibitor completely prevented cleavage of ${ }^{125} \mathrm{I}$-Factor IX because the radioactivity profile was identical to that of ${ }^{125} \mathrm{I}$-Factor IX incubated with buffer. The results were comparable with celiteadsorbed activated contact product and all different dilutions of factor XIa. Control IgG had no effect on ${ }^{125} \mathrm{I}$-Factor IX cleavage.

Factor XIIa activation of Factor XI. Factor XIIa cleaved ${ }^{125} \mathrm{I}$-Factor XI to form Factor XIa (mol wt 80,000 ) with heavy chain (mol wt 50,000 ) and light chain (mol wt 36,000 ) (11) shown on 10\% SDS-PAGE along with the radioactivity profile of native ${ }^{125} \mathrm{I}-\mathrm{Fac}-$ tor XI (Fig. 5). Preincubation of ${ }^{125}$ I-Factor XI with inhibitor prevented cleavage of Factor XI by Factor XIIa. Identical results were obtained when celite adsorbed activated contact product (or the different dilutions of Factor XIIa) was used. Control IgG had no effect of ${ }^{125} \mathrm{I}$-Factor XI activation.

HMWK Binding. ${ }^{125} \mathrm{I}-\mathrm{Factor} \mathrm{XI}$ binds to HMWK immobilized on the surface of polypropylene tubes compared with albumin-coated controls. This binding was prevented by preincubation of ${ }^{125} \mathrm{I}$-Factor XI with inhibitor but not purified control IgG (Fig. 6). Preincubation of HMWK-coated plates with inhibitor, followed by washing and then incubation with ${ }^{125} \mathrm{I}$-Factor XI had no effect on ${ }^{125}$ I-Factor XI HMWK binding. The antibody, therefore, prevents Factor XI HMWK 
complex formation by specifically combining with Factor XI.

\section{DISCUSSION}

The data shown in Table I indicate that the inhibitor present in this patient was a polyclonal IgG antibody mainly of heavy chain subclass 4 . Evidence that the antibody was specific for Factor XI and no other coagulation factor is presented in Table II and Figs. 2 and 3. Complex formation of Factor XI with its antigen prevented cleavage and activation by Factor XIIa cleavage and activation of Factor IXa, as well as complex formation with HMWK.

Based on the functional consequences of the antibody Factor XI complex, implications for the physiology of Factor XI are considered. The high titer of inhibitor resulted in extremely low levels of Factor XI, and aPTT was markedly prolonged ( $>400 \mathrm{~s})$ in the presence of inhibitor compared with previous values (aPTT in the range of 180 to $200 \mathrm{~s}$ ). The additional prolongation of the clotting time implies inactivation of a small amount of residual Factor XI activity in

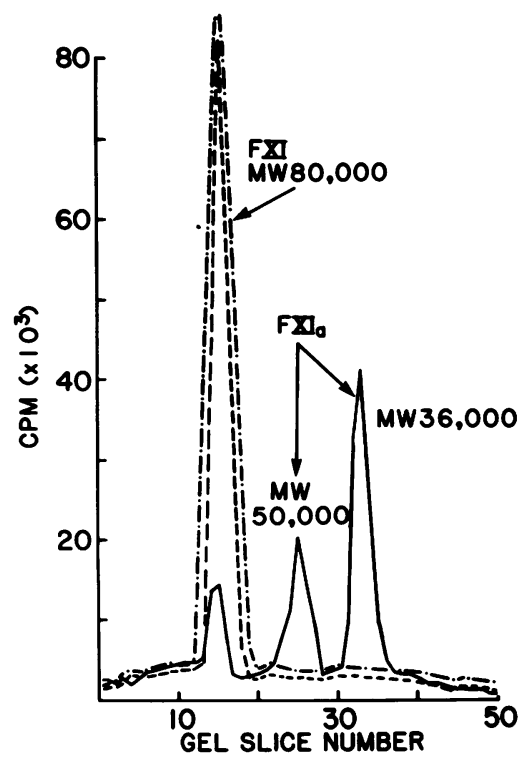

FIgure 5 Cleavage products of FXI activation (10\% SDS gels, reduced). $10 \%$ SDS-PAGE of reduced ${ }^{125} \mathrm{I}$-Factor XI (- - : mol wt 80,000) showing cleavage pattern with formation of Factor XIa [ $(-)$ consisting of heavy chain (mol wt 50,000) and light chain (mol wt 36,000)] by Factor XIIa or celite activated contact product. - - - shows the radioactivity profile of ${ }^{125} \mathrm{I}$-Factor XI, if the tracer was preincubated with purified patient IgG and the Factor XIIIa was then added. Data shown correspond to an experiment with $5 \mu$ l of partially purified inhibitor or saline preincubated for $2 \mathrm{~h}$ at $37^{\circ} \mathrm{C}$ with $5 \mu \mathrm{l}$ of ${ }^{125} \mathrm{I}-\mathrm{Factor} \mathrm{XI}(4 \mu \mathrm{g} / \mathrm{ml})$ followed by the addition of $5 \mu \mathrm{l}$ of Factor XIIa $(2 \mu \mathrm{g} / \mathrm{ml})$ and $3 \mathrm{~h}$ at $37^{\circ} \mathrm{C}$. Samples were then treated as described in Fig. 4.

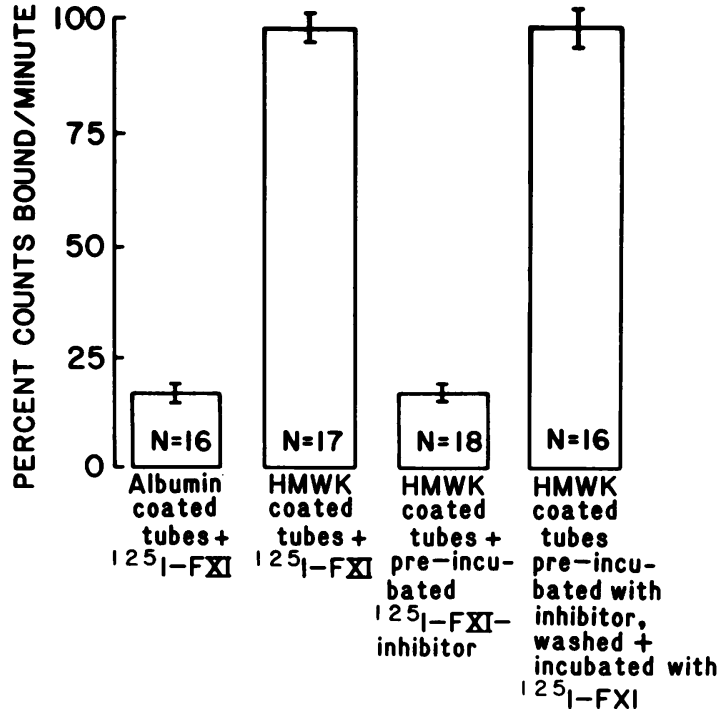

Figure 6 Influence of the inhibitor on the binding of ${ }^{125} \mathrm{I}$ Factor XI to high molecular weight kininogen immobilized on a polypropylene surface (see text for details). $100 \%$ binding represents the amount of ${ }^{125} \mathrm{I}-$ Factor XI bound to HMWK-coated tubes in the absence of inhibitor.

turn implying that the congenital deficiency state in this patient was incomplete despite $1 \%$ Factor XI activity.

The hemostatic consequences of complete deficiency of Factor XI may be inferred from the presenting clinical syndrome: a major progressive bleed, without known injury, refractory to conventional therapy but apparently responsive to an alternate clot-promoting agent. Severe localized bleeding may have been due to local factors in addition to systemic clotting abnormalities because the previous hematoma in the left thigh may have distorted the vasculature in this region. However, the prompt clinical response to systemic infusion of activated prothrombin complex suggested that the critical cause of hemorrhage was a block in clotting system activation. The clinical presentation and its reponse to treatment suggest that Factor XI does participate in normal hemostasis. The severity of his initial left thigh hemorrhage contrasts with his subsequent clinical course. Unlike patients with hemophilia due to deficiency of Factor VIII or IX, he has not had frequent bleeding, having had only one recognized hemorrhage in 1978 , suggesting that severe Factor XI deficiency does not cause as serious a hemostatic defect as Factor VIII or IX deficiency. These observations suggest that activation of Factor XI or IX does not occur exclusively in series because one would then expect Factor VIII, IX, or XI deficiency to produce bleeding diatheses of similar degree. In fact there is evidence of an alternate mechanism for activating Factor IX via tissue thromboplastin and 
Factor VII (23-25). But this mechanism would suggest that Factor XI is not essential for hemostasis. It has been suggested that platelets can activate Factor XI directly bypassing Factor XII (26-28), but this thesis is controversial (29-30). The rarity of a hemorrhagic diathesis in Factor XII deficiency (31-32) contrasts with the syndrome of severe Factor XI deficiency, suggesting an alternative mechanism for activating Factor XI.

From the practical standpoint, activated prothrombin complex appeared to stop bleeding promptly. The patient's uneventful course during his most recent bleed, when activated prothrombin complex was begun immediately, contrasts with the prior episode. In conclusion, the clinical course of this patient and characterization of his Factor XI inhibitor support an essential role for Factor XI in hemostasis.

\section{ACKNOWLEDGMENTS}

We are grateful to Dr. C. Y. Liu for his constructive advice; Drs. W. Kisiel, K. Kurachi, I. Ohkubo, and E. Davie for invaluable assistance in the isolation of Factors IX and XI; Dr. A. Kaplan for generously allowing us to use his immunoadsorption column and for helpful suggestions; and to Dr. J. Griffin for kindly providing details of his Factor XI purification and labeling procedures. Dr. Jeffrey Wasser was a major participant in the management of the patient and in the initial detection of the antibody.

The work was supported by research grants from the $\mathrm{Na}$ tional Institutes of Health (HL-15486, 07461, 21006, and 15596).

\section{REFERENCES}

1. Josephson, A. M., and R. Lister. 1957. Demonstration of a circulating anticoagulant in plasma thromboplastin antecedent deficiency. J. Clin. Invest. 37: 148-152.

2. Shapiro, S. S., and M. Hultin. 1975. Acquired inhibitors to the blood coagulation factors. Semin Thromb. Hemostasis. 1: 336-385.

3. Michaelis, L. 1931. Acetate-Barbital Buffer. Biochem. Z. 234: 138-141.

4. Finlayson, J. S. 1968. Chromatographic purification of fibrinogen. In Fibrinogen. Koloman Laki, editor. Marcel Dekker, Inc. New York 39-59.

5. Deutsch, H. F. 1967. In Methods in Immunology Immunochemistry. C. A. Williams and M. W. Chase, editors. Academic Press, Inc., New York. 1: 318-325.

6. Goding, J. W. 1976. Conjugation of antibodies with fluorochromes: modifications to standard methods. J. Immunol. Methods. 13: 215-226.

7. Pharmacia Fine Chemicals. 1979. Affinity Chromatography, Prinicples and Methods, Piscataway, NJ.

8. Mancini, G., A. O. Carbonara, and J. F. Hermans. 1965 Immunochemical quantitation of antigens by single radial immunodiffusion. Immunochemistry. 2: 235-254

9. Ouchterlony, O. 1948. Antigen-antibody reactions in gels. Ark. Kemi. 26(band 2GB, 14): 1-9.

10. Heck, L. W., and A. P. Kaplan. 1974. Substrates of Hageman Factor. J. Exp. Med. 140: 1615-1630.

11. Bouma, B. N., and J. H. Griffin. 1977. Human blood coagulation Factor XI. J. Biol. Chem. 252: 6432-6437.
12. Kaplan, A. P., and K. F. Austen. 1972. The fibrinolytic pathway of human plasma. J. Exp. Med. 136: 13781393.

13. Weber, K., and M. Osborn. 1969. The reliability of molecular weight determinations by dodecyl sulfate-polyacrylamide gel electrophoresis. J. Biol. Chem. 244: 4406-4412.

14. Amphlett, G. W., W. Kisiel, and F. Castellino. 1981. The interaction of calcium with human factor IX. Arch. Biochem. Biophys. 208: 576-585.

15. Thompson, A. R. 1977. Factor IX antigen by radioimmunoassay. J. Clin. Invest. 59: 900-910.

16. McConahey, P. J., and F. J. Dixon. 1966. A method of trace iodination of proteins for immunologic studies. Int. Arch. Allergy. Appl. Immunol. 29: 185-189.

17. Østerud, B., and S. I. Rapaport. 1980. Activation of ${ }^{125} \mathrm{I}-$ Factor IX and ${ }^{125} I$-factor $X$ : effect of tissue factor and Factor VII, Factor $\mathrm{Xa}$ and thrombin. Scand. J. Haem. 24: 213-226.

18. Nossel, H. L. 1964. In The Contact Phase of Blood Coagulation. Blackwell Scientific Publications Ltd., Oxford, England. 124-125.

19. Thompson, R. E., R. Mandle, Jr., and A. P. Kaplan. 1979. Studies of binding of prekallikrein and factor XI to high molecular weight kininogen and its light chain. Proc. Nat. Acad. Sci. U. S. A. 76: 4862-4866.

20. Nossel, H. G., J. Niemetz, S. A. Waxman, and S. L. Spector. 1969. Defibrination syndrome in a patient with chronic thrombocytopenic purpura. Am. J. Med. 46: 591-598.

21. Lowry, O. H., N. J. Rosebrough, L. A. Farr, and R. J. Randall. 1951. Protein measurement with the Folin Reagent. J. Biol. Chem. 193: 265-275.

22. Di Scipio, R. G., K. Kurachi, and E. W. Davie. 1978. Activation of human factor IX (Christmas factor). J. Clin. Invest. 61: 1528-1538.

23. Østerud, B., and S. I. Rapaport. 1977. Activation of factor IX by the reaction product of tissue factor and factor VII: additional pathway for initiating blood coagulation. Proc. Nat. Acad. of Sci. U. S. A. 74: 5260-5264.

24. Zur, M., and Y. Nemerson. 1980. Kinetics of factor IX activation via the extrinsic pathway. J. Biol. Chem. 255: 5703-5707.

25. Jesty, J., and S. A. Silverberg. 1979. Kinetics of the tissue factor-dependent activation of coagulation factors IX and $X$ in a bovine plasma system. J. Biol. Chem. 254: 12337-12345

26. Walsh, P. N. 1972. The effects of collagen and kaolin on the intrinsic coagulant activities of platelets. $\mathrm{Br} . J$. Haematol. 22: 393-405.

27. Walsh, P. N., and M. S. Lipscomb. 1979. Human platelets and Factor XI. J. Clin. Invest. 63: 1006-1014.

28. Walsh, P. N., and J. H. Griffin. 1981. Contributions of human platelets to the proteolytic activation of blood coagulation factors XII and XI. Blood. 57: 106-118

29. Vicic, W. J., O. D. Ratnoff, H. Saito, and G. H. Goldsmith. 1979. Platelets and surface-mediated clotting activity. Br. J. Haematol. 43: 91-98.

30. Østerud, B., E. Harper, S. I. Rapaport, and K. K. Levine. 1979. Evidence against collagen activation of platelet associated factor XI as a mechanism for initiating intrinsic clotting. Scand J. Haematol. 22: 205-213.

31. Ratnoff, O. D., and J. E. Colopy. 1955. A familial hemorrhagic trait associated with a deficiency of a clot-promoting fraction of plasma. J. Clin. Invest. 34: 602-613.

32. Rizza, C. R. 1972. In Human Blood Coagulation, Haemostasis and Thrombosis. R. Biggs, editor. Blackwell Scientific Publications Ltd., Oxford, England. 214. 